\title{
Learning analytics to identify the influence of leaders hip on the academic performance of work teams
}

\author{
Ángel Fidalgo-Blanco \\ Technical University of Madrid \\ ETSI MyE, Rios Rosas, 21 \\ 28003-Madrid, Spain \\ +34913367046 \\ angel.fidalgo@upm.es \\ María Luisa Sein-Echaluce \\ University of Zaragoza \\ EINA, María de Luna, 3 \\ 50018 Zaragoza, Spain \\ +34976 761979 \\ mlsein@unizar.es \\ Javier Esteban-Escaño \\ University of Zaragoza \\ EUPLA, Mayor s/n \\ 50100 La Almunia-Zaragoza, Spain \\ +34976600813 \\ javeste@unizar.es \\ Francisco J. García-Peñalvo \\ University of Salamanca \\ Faculty of Science, Plaza de los Caídos $\mathrm{s} / \mathrm{n}$ \\ 37008 Salamanca, Spain \\ +34923294400 \\ fgarcia@usal.es \\ Miguel Ángel Conde \\ University of León \\ Escuela de Ingenierías, Campus de Vegazana s/n, \\ 24071 León, Spain \\ +34987293418 \\ miguel.conde@unileon.es
}

\begin{abstract}
In the academic context teamwork has a dual mission: to train students in teamwork competence and the active participation of students in their own learning. Authentic leadership of teams is the key to both goals. This paper presents a research which relates leadership, team grades (individual and group) and student-student interactions. The CTMTC teamwork method is used, as it allows continuous monitoring of teamwork and evaluates the work of the leader and the rest of the team members separately. The measurement tools, a survey for the individual opinion on the authentic leader actions, and a learning analytics system to analyze student-student interactions in forums, help to confirm the following hypothesis: that CTMTC encourages leadership role, that leadership skills are related with team grades and that learning analytics systems help predicting the behavior of teams with true leadership.
\end{abstract}

\section{CCS Concepts}




\section{- CCS $\rightarrow$ Applied computing $\rightarrow$ Education $\rightarrow$ Collaborative learning}

\section{Keywords}

Teamwork Competence; Learning Analytics; CTMTC; Leadership.

\section{INTRODUCTION}

Teamwork competencies have been widely demanded by employers [11] and, despite current changes resulting from the implementation of technologies, teamwork proficiency continues being one of the 10 most demanded skills [17]

However, international management organizations also emphasize the importance of teamwork proficiency, The General Secretary of the United Nations includes de TWC amongst ITS Core Competencies that “...refer to the combination of skills, attributes and behavior required of all staff, regardless of their level or function', [5]

Higher education institutions and instructors emphasize the importance of developing teamwork competences on their degree programs too, [2] as international accreditation agencies of university degrees as ABET (Accreditation Board for Engineering and Technology) demand proficiency in teamwork skills on engineering programs [1]

Through teamwork competence, students acquire skills and abilities such as: increased efficiency, greater effectiveness and faster output (through the combination of individual efforts), more thoughtful ideas (from different minds focusing on the same problem) and mutual support and outcomes, using resources more effectively [4]

Within the teamwork competence, the leader role is relevant but requires an advanced knowledge of this competence [20] and must face conflict situations, monitor and ensure that each member of the working team meets their responsibilities, to achieve the expected team results efficiently and effectively.

Teamwork has a dual mission: on the one hand, to train students in teamwork competence; on the other hand cooperative learning improves the specific knowledge of the subject where teamwork occurs. As demonstrated in previous studies [9, 14, 15], teachers evaluate final results of teamwork once students have completed it. With traditional training methods the creation of teamwork individual skills isn't guaranteed and therefore the degree of acquisition of teamwork competence is unknown.

White box methods allow determining the degree of acquisition of teamwork competence; namely methods that allow continuous monitoring of communications between students, the phases of development of teamwork and the final results. The white box method used in this paper is called CTMTC (Comprehensive Training Model of the Teamwork Competence). Among the advantages of CTMTC, we can point out a high degree of satisfaction among students [15], generation of individual evidences [7], group and outcome evidences [14] and applicability in different types of subjects [6]. Therefore this method allows monitoring of communications, activities and processes conducted by the team leader.

However, the problem of white-box methods is the required investment of time to perform continuous monitoring of the monitored competence for each team, either to make decisions or to conduct a formative evaluation [10]. In order to solve this problem, CTMTC requires the support of learning analytics (LA) tools to analyze individual evidence from both team members and the leader. The use of LA tools is useful to predict individual and team grades, monitor teamwork development and make decisions [8].

The current socio-political environment has generated mistrust in individuals of banking and political leaders, driving demand for a new type of leader. One of these new types of leadership is based on positive psychology, where the leader should try to resolve the negative aspects and to promote and develop the positive ones [18]. This approach has been applied in the field of leadership and has proposed a new model called Authentic Leadership. Authentic leaders recognize and appreciate individual differences and are able to identify the talents or positive qualities of people, helping them to strengthen [16]

Given this context, we aim to check the following hypothesis:

H0: CTMTC encourages the creation of Authentic Leadership.

H1: Leaders who have Authentic Leadership skills achieve better grades in their teamwork.

$\mathrm{H} 2$ : The use of LA systems improves prediction of behavior of team with Authentic Leadership.

The next sections include a description of CTMTC, a contextualized implementation of the methodology, the results of the empirical research and the conclusions of the study.

\section{METHODOLOGY}

CTMTC is a "white box" teamwork method. It continuously generates evidence of the work of the student in the different phases of teamwork, as well as information about the final results. Both faculty and teams can observe these evidences at any time, and make decisions accordingly.

The "white box" method allows the team leader (and other members) to check the individual responsibility of each team member, the degree of development of the tasks and the evidences that teacher will assess. Therefore, the leader plays an important role in the team in order to transform the group into a high performance team. 
CTMTC is composed of three layers, each of them with specific functions that interact with each other: Conceptual, technological and methodological. Figure 1 depicts an schematic of the CTMTC framework. The purple color $(*)$ is the conceptual layer, the green one $(* *)$ the technology layer and the blue one (***) the methodological layer.

\subsection{Conceptual layer}

The objective of the conceptual layer is to ensure the acquisition of the teamwork competence. In this layer we establish the phases that must comprise the teamwork. The overall aim is that, through these phases, the students acquire skills and use tools similar to those that can be found in the professional environment.

The conceptual framework for this layer is sustained by the design of [19] who specified a set of steps to be followed by small groups. The proposed steps are: Forming, Storming, Norming and Performing. This model has been extended with two new phases: the delivery of the final product of the project and the development of lessons learned. This new model is widely used in the environment of professional and academic excellence, as used in the international accreditation agency IPMA for professional environments [13] and the formation of teamwork in MIT [12].
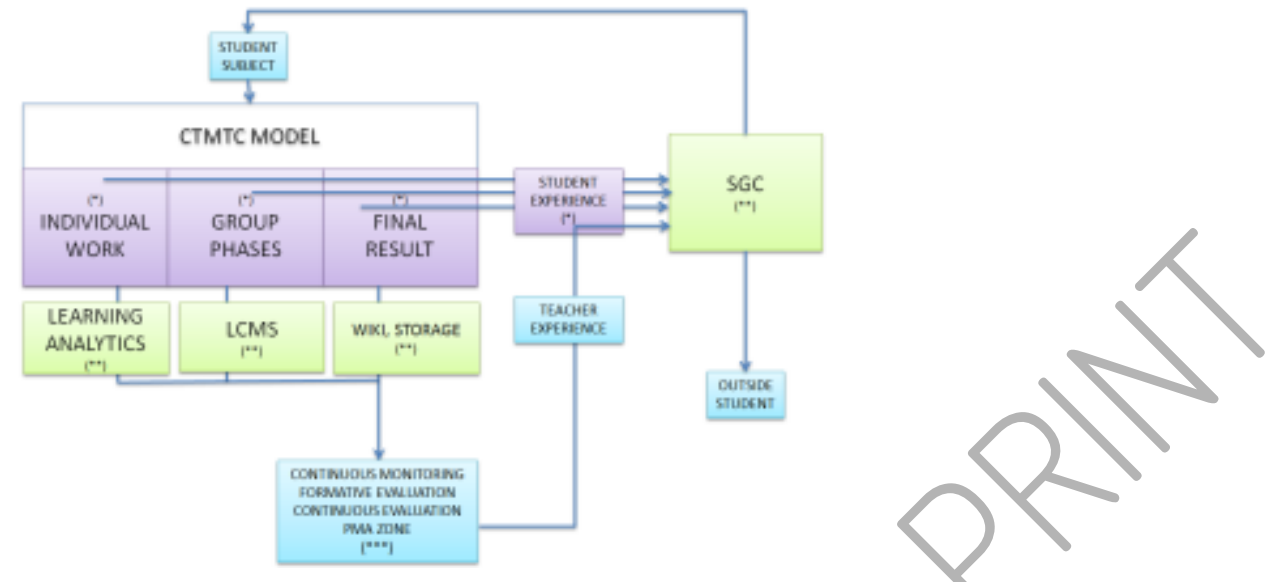

Figure 1. Method CTMTC: Conceptual layer (*), Technological layer (**) and Methodologial layer (***)

The main contributions of the CTMTC to the conceptual framework is that the "organization of the documentation generated during development of the team" is added and a set of evaluable evidences for each one.

Table 1. Overall vision of the conceptual layer of the model

\begin{tabular}{|c|c|c|}
\hline Phase & Group evidences & $\begin{array}{c}\text { Individual evidences } \\
\text { (communication })\end{array}$ \\
\hline Forming & Formed group & $\begin{array}{l}\text { Interactions to choose } \\
\text { team leaders }\end{array}$ \\
\hline Storming & $\begin{array}{l}\text { Mission, objectives, } \\
\text { utility, target audience, } \\
\text { map of } \\
\text { responsibilities, } \\
\text { planning and schedule }\end{array}$ & $\begin{array}{l}\text { Interactions to plan } \\
\text { different phases }\end{array}$ \\
\hline Norming & $\begin{array}{l}\text { Rules designed by the } \\
\text { team }\end{array}$ & $\begin{array}{l}\text { Interactions to develop } \\
\text { the rules and discuss the } \\
\text { viability }\end{array}$ \\
\hline Performing & $\begin{array}{l}\text { Monitoring of daily } \\
\text { evolution. }\end{array}$ & $\begin{array}{l}\text { Interactions for build the } \\
\text { control panel. } \\
\text { Interactions showing the } \\
\text { evolution of each } \\
\text { individual (personal } \\
\text { work journal reports) }\end{array}$ \\
\hline Deliverable & $\begin{array}{c}\text { Final score, } \\
\text { Content organization }\end{array}$ & $\begin{array}{c}\text { Final online } \\
\text { product. Organization } \\
\text { online content }\end{array}$ \\
\hline $\begin{array}{l}\text { Learned } \\
\text { lessons }\end{array}$ & $\begin{array}{l}\text { Videos with } \\
\text { reflection on the } \\
\text { phases. Videos with } \\
\text { reflection on the final } \\
\text { product }\end{array}$ & $\begin{array}{l}\text { Videos stored in a } \\
\text { knowledge management } \\
\text { system to facilitate its } \\
\text { use by future teams. }\end{array}$ \\
\hline
\end{tabular}


Individual evidence is also added to the conceptual layer. Individual evidence considers communication between students during the different phases.

\subsection{Technological layer}

The aim of this layer is to provide support for the completion of each phase, in order to track and manage group and individual evidences continuously.

Team members, the leader and faculty have the same access to the technology layer. Therefore, all those actors involved in the teamwork can accurately and timely monitor any stage of development of teamwork.

In this layer two groups of technologies are involved: those associated with the development of teamwork and those associated with evidence management.

From a teamwork development perspective, the framework allows students to achieve higher performance in each phase and leaves evidences of the work completed (group and individual). The technology is scalable, admitting the use of a single system, such as a Learning Management System (LMS) like Moodle (http://moodle.org), but also a greater variety of technological tools for different purposes, for instance:

- LMS: Forums used for student-student interaction and internal LMS wikis to collect group evidences of the 4 phases (Forming, Storming, Norming and Performing)

- $\quad$ Online Storage System: Organization of the documentation developed in each phase, as well as the final result.

- Wiki and web pages: Delivery of the final work.

Regarding collection and management of evidences, the technology facilitates completion of tasks by teachers and students. Teachers use tools to monitor and assess (formative and summative) the acquisition of the teamwork competence. Students use technology to find useful information, to acquire the competence and to facilitate the development of the academic work. This information has the form of lessons learned from and for other teams. Several technologies support evidence collection and management:

- Knowledge Management Systems that store, sort and organize the lessons learned and the reflections of different teamwork

- Learning Analytics to continuously monitor individual evidence and decision making.

\subsection{Methodological layer}

The purpose of this layer is to facilitate training and assessment strategies to foster the creation of high performance teams, where each team member should understand the development of teamwork, and where individuals acquire the competence of teamwork that will help them both on their academic and professional careers.

From the teaching staff point of view, the framework presents several advantages:

- $\quad$ CTMTC allows formative and summative assessment through individual evidences (communication and student-student interactions), and group results (deliverables at different stages, final deliverables).

- Formative assessment allows teachers to track team evolution, the degree of development and completion of group tasks and the degree of commitment and activity of each team member. These tasks are done by parts throughout individual and group evidence.

- Summative evaluation allows assessment of the degree of acquisition of the teamwork competence. This assessment includes individual, group and outcomes evidences. Summative evaluation can be continuous (partial evaluations are performed during different phases of team work) or finat (including the analysis of the involvement and responsibility of each member of the team, using the partial results of the different phases and the final result)

- Formative or summative evaluation of group evidences is simple. However, assessment of individual evidences is costly because it is associated with a high investment of effort by teachers $[6,8,14,15]$, requiring the application of learning analytics $[6,8,10]$.

From the point of view of the students, the representation of the model focuses on Personalization, Motivation and Active participation (PMA). Personalization or customization refers to the teaching resources and personal attention by teachers, motivation refers to authentic leadership and empowerment of students, and active participation includes decision making, assumption of responsibilities and cooperative participation of students.

\section{IMPLEMENTATION OF THE METHODOLOGY}

The methodology was implemented in the course of Computer Science and Programming, a first-year course of the Technical University of Madrid. The course had 28 participating teams, with an average of 6 people per team (a total of 168 students). Work teams were set at the beginning of the course (February 2016) and work could be completed until the end of the course (May 2016). The amount of in-class time dedicated to this work was 10 hours. In-class sessions consisted of a presentation and explanation of the methodology, and sharing the progress of each team with the whole class. This work had a specific weight of $15 \%$ of the final course grade.

The implementation was carried out in four phases: 1) Students performed the teamwork, using the CTMTC while formative evaluation of each team was performed at different stages; in-class formative evaluation was used as a resource training for all teams; 2) Teams present the deliverables (work, lessons learned and temporary files); 3) Students complete a survey prior to grading; 4) Assessment of individual skills using the LA system, and manual assessment of group evidences and results. 
Phase 1: Teamwork development.

This process is the key to the development of teamwork competence. Students must produce evidences through student-student interactions. Formative evaluation of evidences occurs at group and individual levels. Group evidences are evaluated from the findings and summaries of each team in Moodle. Figure 2a shows poor structuring: the phases are not in order, and there are missing activities. Individual evidence is analyzed through the system. Figure $2 b$ shows that the 3 members of the team (student 1 , student 2 and student 3 ) have done less workload, and clearly student 2 is not participating. Based on the data, instructors may track interactions and dates of participation of people with less workload. The results of the analysis may be used as a teaching resource to show students how they should not carry out their assignment.

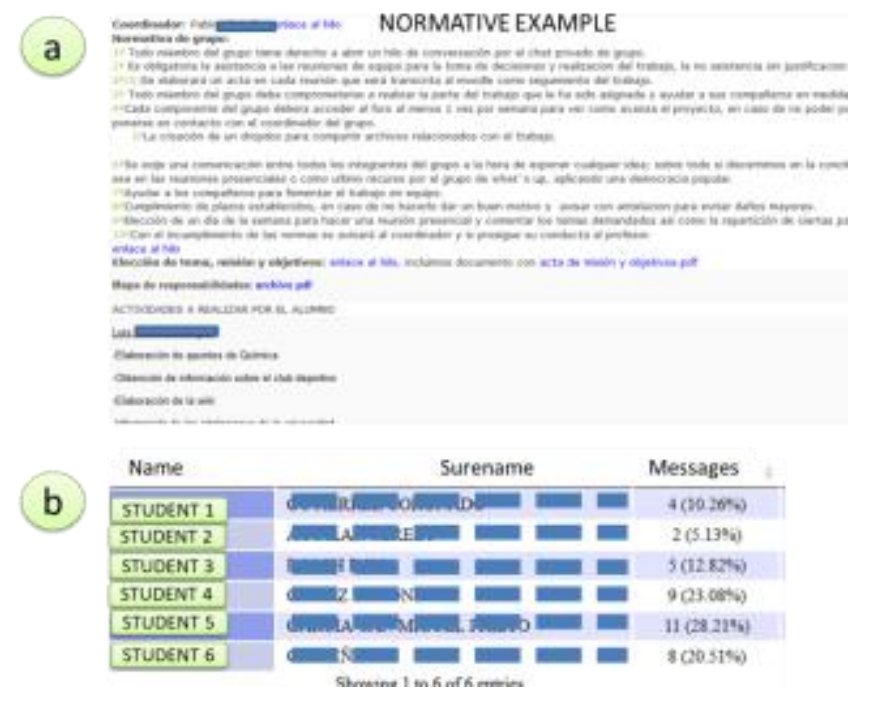

Figure 2. Formative evaluation

Phase 2: Presentation of deliverables. Figure 3 shows the results that teams must submit (Figure $3 a$, the final product; Figure $3 b$, video of lessons learned; and Figure 3c, content organization).
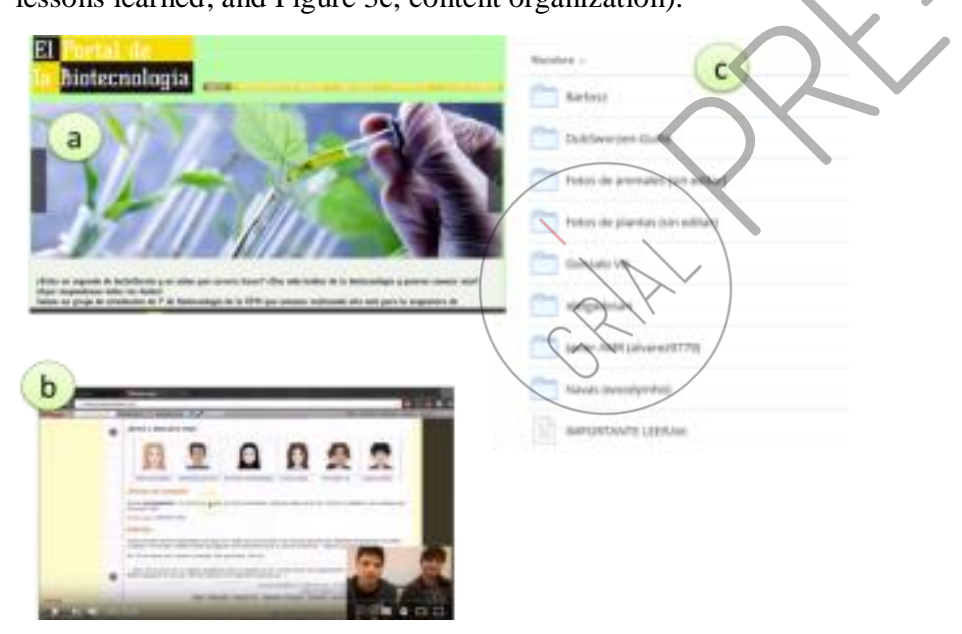

Figure 3. Deliverable examples

Phase 3: Survey completion to assess Authentic Leadership. Students are separated into two groups: team leaders, and the rest of students. The results of this survey are discussed in the results and discussion section.

The survey is the "Authentic Leadership Questionnaire" (ALQ), designed by Walumbwa and based on the theory of "Authentic Leadership” [21]. In 2011, this survey was translated to Spanish, validated again, and applied to a sample of 600 respondents [16].

ALQ assesses 4 dimensions with Likert-5 scales:

- Self-awareness

- Transparency

- Ethical-moral

- $\quad$ Balanced processing 
Phase 4. Final evaluation. The process is identical to the formative evaluation, but using the final evidences. Student-student interactions are organized into threads, with each thread corresponding to a given stage. The LA system shows the start and end dates of each phase, as well as student-student interactions in each of them.

Figure 4 shows the results of the analysis with the LA tool. In Figure 4a presents the start date of each phase, the number of messages exchanged by students and their relative effort. Figure $4 \mathrm{~b}$ displays the interactions within the group and the level of participation of each member of the team. This figure shows that student 7 (the team leader) is the one who has participated the most and that there are indications that the leader proposed the mission and objectives, but there has not been much debate to define them.

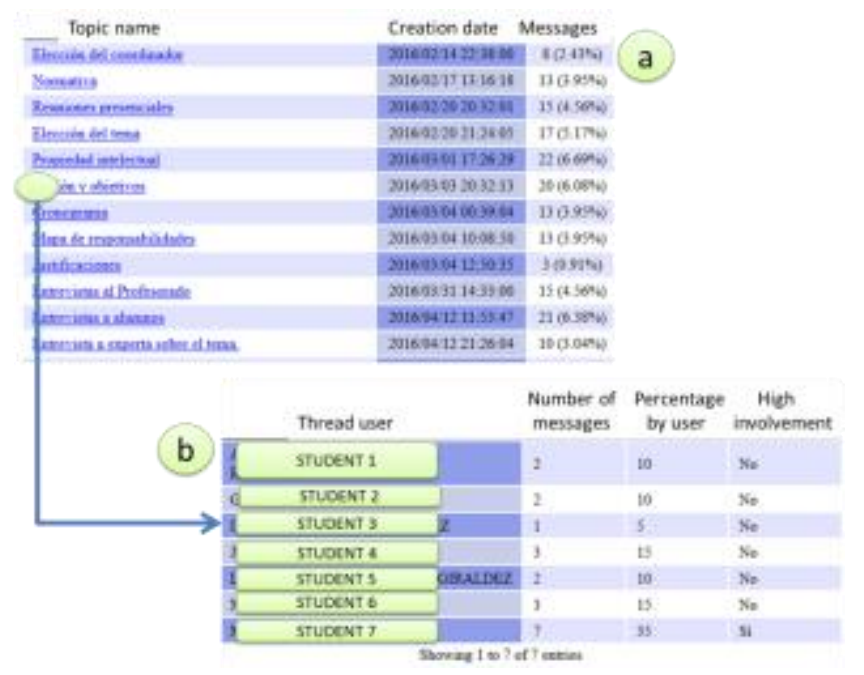

Figure 4. Learning Analytics data

\section{RESULTS}

ALQ comprises 16 questions. In the Spanish version of the questionnaire, questions ALQ13 to ALQ16 represent self-awareness, ALQ1 to ALQ5 represent transparency, ALQ6 to ALQ9 represent the ethical-moral dimension, and ALQ10 to ALQ12 represent balanced processing. Calculation of the score for each leader consists on simple addition of the scores of each dimension. Since each dimension has a different measurement scale, all results are then normalized to a 10-point scale.

The final grade of each student is calculated by aggregating three marks: the grade of the work presented by the team (result grade), the individual grade of each student (individual grade), and the grade given to the group for their collaborative work (teamwork grade). Furthermore, the number of messages per user in each group posted in the forums is also taken into account.

The study first investigates whether there is any relationship between CTMTC and features of Authentic Leadership.

Table 2 presents the results of assessment of whether the work done during the course has a positive influence on the characteristics of Authentic Leadership of coordinators. Results in Table 2 show mean scores of coordinators, normalized to a 10-point scale, with $\mathrm{N}$ being the number of groups.

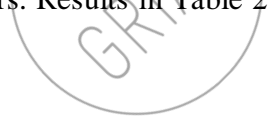

Table 2. Normalized mean in Authentic Leadership

\begin{tabular}{|l|c|c|c|}
\hline \multicolumn{1}{|c|}{ Dimension } & Mean & Std. Dev. & N \\
\hline Self-awareness & 7.74 & 1.25 & 25 \\
\hline Transparency & 8.34 & 0.71 & 25 \\
\hline Ethical-moral & 8.24 & 1.09 & 25 \\
\hline Balanced processing & 8.77 & 1.05 & 25 \\
\hline
\end{tabular}

The study analyzes the relationship between each of the measures of authentic leadership obtained and grades obtained by the leader and the rest of group members, through a correlation bilateral Spearman test. The results yield a strong positive correlation between Selfawareness and academic results (see Table 3 ).

Table 3. Correlation between grades and self-awareness

\begin{tabular}{|l|c|c|}
\hline \multicolumn{1}{|c|}{ Variable } & Rho & $\mathrm{p}$-value \\
\hline Final grade (leader) & 0.56 & $0.004(<0.01)$ \\
\hline Final grade (teammates) & 0.58 & $0.002(<0.01)$ \\
\hline
\end{tabular}




\begin{tabular}{|l|l|l|}
\hline Individual grade (leader) & 0.60 & $0.002(<0.01)$ \\
\hline Individual grade (teammates) & 0.65 & $0.000(<0.01)$ \\
\hline Teamwork grade & 0.40 & $0.049(<0.05)$ \\
\hline
\end{tabular}

Regarding transparency, the results show only a positive correlation between grades and ALQ3 (Table 4).

Table 4. Correlation between ALQ3 and grades

\begin{tabular}{|l|l|l|}
\hline Variable & Rho & p-value \\
\hline Leader final grade & 0.54 & $0.005(<0.01)$ \\
\hline Messages average & 0.51 & $0.009(<0.01)$ \\
\hline Teamwork grade & 0.50 & $0.005(<0.01)$ \\
\hline Leader individual grade & 0.46 & $0.096(<0.01)$ \\
\hline
\end{tabular}

In order to discover the influence of authentic leadership on individual student behavior, we also analyzed the exchange of messages within the groups -from the LA tool- and found interesting relationships between some of the variables that form the dimensions of authentic leadership.

Table 5. Linear regression model total post

\begin{tabular}{|l|l|l|l|l|}
\hline & Estimate & Std Err. & t-value & $\operatorname{Pr}(>|\mathbf{t}|)$ \\
\hline (Intercept) & -5.183 & 22.803 & -0.220 & 0.823 \\
\hline ALQ1 & -3.582 & 1.624 & -2.206 & 0.042 \\
\hline ALQ2 & 4.628 & 1.656 & 2.795 & 0.013 \\
\hline ALQ4 & 2.857 & 1.484 & 1.925 & 0.072 \\
\hline ALQ6 & 4.194 & 1.607 & 2.610 & 0.019 \\
\hline ALQ9 & -3.335 & 1.297 & -2.571 & 0.021 \\
\hline ALQ11 & -3.996 & 1.487 & -2.688 & 0.016 \\
\hline ALQ14 & 7.823 & 1.796 & 4.356 & 0.000 \\
\hline ALQ15 & -3.821 & 1.654 & -2.310 & 0.035 \\
\hline
\end{tabular}

The LA system analyzes student-student interactions performed in the LMS system. With data generated by the LA system, the research builds a linear regression model with a maximum error of $10 \%$, to predict the number of messages per user sent in a group based on answers to the ALQ (see Table 5).

The model obtained in Table 5 explains $60.04 \%$ of the variance of the variable "number of messages sent per user in a group", and Figure 5 shows the basic graphical adjustment of this model. 

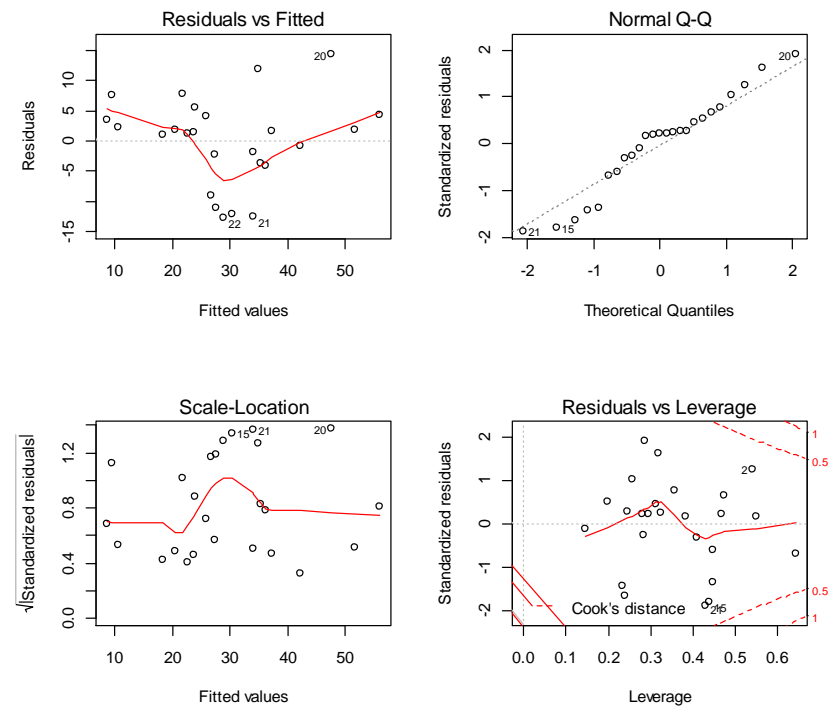

\section{CONCLUSIONS}

Figure 5: Linear regression model total posts

The results presented in Table 2 support $\mathrm{HO}$ because coordinators have the characteristics of authentic leadership: the lowest average obtained in one of the dimensions is 7.4 over 10 (self-awareness). Therefore, we can conclude that CTMTC contributes to the formation of authentic leadership.

Table 3 shows that there is a strong positive correlation between self-awareness and coordinator and group grades. Other evidences support the conclusion that, albeit not that strong, there is influence between transparency and coordinator and group grades (Table 4). These results support $\mathrm{H} 1$, and therefore leaders who exhibit characteristics of authentic leadership achieve better grades in teamwork. The results of the test are a bit better that those obtained by [21] and [16].

The linear regression model (Table 5) contains components of each of the 4 dimensions of authentic leadership, the achieved model. This model may be used to predict the number of messages exchanged by students according to the results of the ALQ, and supports H2. Furthermore, and since there is a relationship between the number of messages and the characteristics of true leadership, it could be possible to identify authentic leaders from the number of messages exchanged because higher leadership scores correspond to generation of higher number of messages.

One of the future work lines is based on identifying processes and activities associated to authentic leadership in the academic teamwork.

\section{ACKNOWLEDGMENTS}

We would like to thank the Government of Aragøn, the European Social Fund and the Ministry of Education of the Region of CastillaLeón for their support. Finally, the authors-would like to express their gratitude to the research groups (LITI, http://www.liti.es; GIDTIC, http://gidtic.com and GRIAL, http://grial.usal.es).

\section{REFERENCES}

[1] ABET 2015. Accreditation Policy and Procedure Manual. http://www.abet.org/wp-content/uploads/2015/05/A001-15-16Accreditation-Policy-and-Procedure-Manual-03-19-151.pdf Accessed: 2016-09-20.

[2] ANECA 2013. Guía de apoyo para la redacción, puesta en práctica y evaluación de los resultados de aprenedizaje. http://www.aneca.es/content/download/12765/158329/file/learningoutcomes_v02.pdf Accessed: 2016-09-20.

[3] Avolio, B.J. and Gardner, W.L. 2005. Authentic leadership development: Getting to the root of positive forms of leadership. Leadership Quarterly. 16, (2005), 315-338.

[4] Boundless 2016. Advantages of Teamwork. Boundless. http://www.boundless.com Accessed: 2016-09-20.

[5] Competencies for the future. United Nations: 2014. https://careers.un.org/lbw/attachments/competencies_booklet_en.pdf. Accessed: 2016-09-20.

[6] Conde, M.Á., Hernández-García, Á., García-Peñalvo, F.J., Fidalgo, Á. and Sein-Echaluce, M. 2016. Evaluation of the CTMTC Methodology for Assessment of Teamwork Competence Development and Acquisition in Higher Education. LNCS. 9753, (2016), $1-12$.

[7] Fidalgo, Á., Conde, M.Á., Sein-Echaluce ML, García-Peñalvo, F., Sein-Echaluce, M. and García-Peñalvo, F.J. 2014. Diseño y desarrollo de un sistema basado en Learning Analytics para evaluar la competencia de trabajo en equipo Design and development of a Learning Analytics System to evaluate group work competence. 2014 9th Iberian Conference on Information Systems and Technologies (CISTI) (2014), 1138-1143. 
[8] Fidalgo-Blanco, Á., Sein-Echaluce, M.L., García-Peñalvo, F.J. and Conde, M.Á. 2015. Using Learning Analytics to improve teamwork assessment. Computers in Human Behavior. 47, (2015), 149-156.

[9] Fidalgo-Blanco A, Léris, D Sein-Echaluce ML, G.-P.F. 2013. Indicadores para el seguimiento y evaluación de la competencia de trabajo en equipo a través del método CTMTC. Aprendizaje, Innovación y Competitividad. S.-E.M. Fidalgo-Blanco A, ed. Fundación Universidad Politécnica de Madrid. 280-285.

[10] Fidalgo-Blanco A, L.D., Sein-Echaluce ML, G.-P.F. and García-Peñalvo, F.J. 2015. Monitoring Indicators for CTMTC: Comprehensive Training Model of the Teamwork Competence in Engineering Domain. International Journal of Engineering Educationv. 31, 3 (2015), 829-823.

[11] Fredericks Volkwein, J., Lattuca, L.R., Terenzini, P.T., Strauss, L.C. and Sukhbaatar, J. 2004. Engineering Change: A Study of the Impact of EC2000*. International Journal of Engineering Education. 20, 3 (2004), 318-328.

[12] HR at MIT | Learning \&amp; Development | Using the Stages of Team Development: http://hrweb.mit.edu/learningdevelopment/learning-topics/teams/articles/stages-development. Accessed: 2016-09-20.

[13] IPMA 2006. ICB-IPMA Competence Baseline Version 3.0. International Project Management Association. http://www.ipma.world/assets/ICB3.pdf Accessed: 2016-09-20.

[14] Lerís, D., Fidalgo, Á. and Echaluce, M.L.S. 2014. A comprehensive training model of the teamwork competence. International Journal of Learning and Intellectual Capital. 11, 1 (2014), 1-19.

[15] Léris, D., Fidalgo-Blanco, Á. and Sein-Echaluce, M.L. 2012. La competencia del trabajo en equipo Un análisis al comienzo de los grados universitarios. XIV Simposio Internacional de Informática Educativa (Andorra la Vella, 2012), 175-180.

[16] Moriano, J.A., Molero, F. and Lévy, J.. J. 2011. Liderazgo auténtico. Concepto y validación del cuestionario ALQ en España. Psicothema. 23, 2 (2011), 336-341.

[17] Pérez Huertas JL 2016. Posiciones y Competencias más demandadas. Informe EPYCE 2015.

[18] Seligman, M.E.P. and Csikszentmihalyi, M. 2000. Positive psychology: An introduction. American Psychologist. 55, 1 (2000), 514.

[19] Tuckman, B.W. 1965. Classics for Group Facilitators Developmental Sequence in Small Groups'. Psychological Bulletin. 63, 6 (1965), 384-399.

[20] Villa Sánchez, A. and Poblete Ruiz, M. 2007. Una propuesta para la eualuación de las competencias genéricas. Universidad de Deusto.

[21] Walumbwa, F.O., Avolio, B.J., Gardner, W.L., Wernsing, T.S. and Peterson, S.J. 2007. Authentic Leadership: Development and Validation of a Theory-Based Measure. Journal of Management. 34, 1 (Oct. 2007), 89-126.

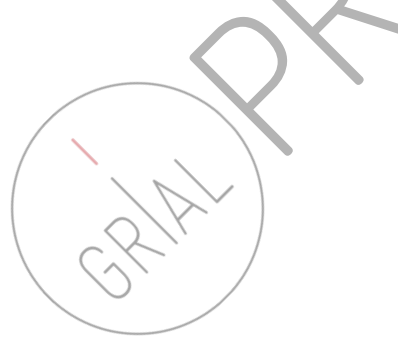

